\title{
Paradojas entre el decir y el hacer acerca de la diversidad en estudiantes de educación primaria de Pereira, Colombia
}

\author{
Paradoxes between saying and doing about diversity in \\ primary education students of Pereira, Colombia

\begin{abstract}
Martha Cecilia Gutiérrez Giraldo $\&$ Carolina Franco Ossa ${ }^{\mathrm{b}}$ [orcid.org0000-0002-1221-2137]

bUniversidad Tecnológica de Pereira, Pereira, Colombia. carofranco@utp.edu.co
\end{abstract} \\ aUniversidad Tecnológica de Pereira, Pereira, Colombia. \ mgutierrez@utp.edu.co \\ [orcid.org/0000-0001-9439-9013]
}

\section{RESUMEN}

El artículo tiene como propósito evidenciar las concepciones de diversidad en estudiantes de primaria, en prácticas de Educación para la Ciudadanía basadas en el análisis de cuestiones controvertidas o de problemas sociales relevantes. La investigación es cualitativa y la estrategia es el estudio de casos, busca profundizar en las concepciones de diversidad de los estudiantes en contextos naturales de aula. Los tres grupos seleccionados suman 75 niños y niñas entre los seis y los nueve años de edad, procedentes de familias de distintas regiones de Colombia, que han llegado a Pereira por ser esta, una ciudad receptora de población en situación de riesgo social. Los resultados identifican prácticas de enseñanza basadas en perspectivas de educación para una ciudadanía nacional, en las que los estudiantes reconocen verbalmente semejanzas y diferencias biológicas y culturales entre ellos y, a su vez, rechazan o discriminan a los compañeros, principalmente, por prejuicios o estereotipos sociales.

PALABRAS CLAVE: Diversidad, Educación para la Ciudadanía, Educación Básica, democracia social, concepciones.

\section{ABSTRACT}

The purpose of the article is to demonstrate the conceptions of diversity in elementary school students, in Citizenship Education practices based on the analysis of controversial issues or relevant social problems. The research is qualitative and the strategy is the study of cases, it seeks to deepen the conceptions of diversity of students in natural classroom contexts. The three selected groups add up to 75 boys and girls between the ages of six and 
nine, from families from different regions of Colombia, who have come to Pereira because it is a city that receives a population at social risk. The results identify teaching practices based on educational perspectives for a national citizenship, in which students verbally acknowledge biological and cultural similarities and differences between them and, in turn, reject or discriminate against their peers, mainly due to prejudices or stereotypes social.

KEY WORDS: Diversity, Citizenship Education, Basic Education, social democracy, social justice, conceptions

\section{INTRODUCCIÓN}

La Educación para la Ciudadanía debe centrar su atención en la formación de estudiantes capaces de identificar y analizar problemas e injusticias sociales, buscar posibilidades para su transformación, y de actuar para conseguir un mundo más justo y democrático. Sin embargo, distintos estudios (Ruiz, 2018; Schulz, Ainley, Cox \& Friedman, 2018; Jimémez \& Goenechea, 2014) encuentran que la escuela homogeniza los procesos de formación, desconoce las particularidades, las necesidades y las demandas del contexto, situación que dificulta la transferencia de los saberes escolares a la realidad cotidiana de los estudiantes.

Tradicionalmente, la educación ha unificado la formación dentro de un modelo de valores universales, de culturas dominantes que homogenizan las costumbres de los grupos hegemónicos presentes en los espacios escolares y, cuando los grupos se resisten, afrontan actitudes excluyentes y marginadoras.

Entre las alternativas para superar problemas como los enunciados en la Educación para la Ciudadanía y las Ciencias Sociales, está la enseñanza y el aprendizaje de ellas a través del análisis de problemas sociales relevantes (Evans \& Saxe, 1996; Huber, 2004), de cuestiones socialmente vivas (Legardez, 2004), de temas candentes o de cuestiones controvertidas (López, 2011), para favorecer la formación de pensamiento crítico en los niños, las niñas y los jóvenes de los distintos niveles educativos.

Problematizar el conocimiento a enseñar a través del análisis y el debate de problemáticas sociales incómodas y complejas, o de conceptos controvertidos de la sociedad, en los que se relacione el presente con el pasado para buscar posibilidades de cambio en el futuro, motiva a los estudiantes por las Ciencias Sociales y acentúa su compromiso con la participación en búsqueda de alternativas de solución viables a problemáticas de los contextos (Santisteban, 2019, p. 15).

El análisis de temas controvertidos o de cuestiones socialmente vivas en la enseñanza de la Educación para la Ciudadanía, pone en tensión las prácticas sociales establecidas y ayuda a cuestionar las concepciones y las representaciones de estudiantes y docentes sobre el mundo social. Facilita la vinculación de hechos, vivencias y situaciones de discriminación, injusticia o conflictos, con problemáticas sociales cercanas a la vida de los alumnos. Además, desarrolla en estos capacidades de orden superior, a medida que aprenden a discutir sus puntos de vista de manera coherente y argumentada. 
Un tema o cuestión controversial en la Educación para la Ciudadanía es el de la desigualdad y la diversidad, que se desarrolla a continuación, porque es la base de la investigación que da origen a este artículo.

\section{Diversidad- diversidad cultural}

El concepto de diversidad está intrínsecamente ligado al de ciudadanía, entendida esta como la pertenencia a una comunidad política, que implica (Cortina, 2009; Soysal, Baubock \& Bosniak, 2010, p. 36):

- Un status jurídico político con derechos y obligaciones de los que son titulares los miembros de ella y que diferencia a las personas que transitan por el territorio de la comunidad (refugiados, asilados, extranjeros, comerciantes, entre otros).

- Una identidad individual y comunitaria de quienes conforman la comunidad política y las formas como estos se autoreconocen y se autocomprenden, de acuerdo con unos valores políticos o culturales (ciudadanía nacional).

- Un conjunto de prácticas políticas individuales y colectivas derivadas del estatus sociojurídico de los ciudadanos y de sus compromisos identitarios (ferias, fiestas, carnavales, etc.).

En el contexto anterior de la ciudadanía surgen las concepciones de ciudadanía moderna o nacional ligada al Estado-Nación, y de ciudadanía planetaria (Morin, Ciurana \& Motta, 2002), ciudadanía global (Cortina, 2009), o transnacional (Baubock, 2005).

La ciudadanía nacional en los Estados contemporáneos está ligada a los conceptos de Estado y nación, y se refiere al conjunto de personas que habitan un territorio, unidas por una historia y una cultura común que las cohesiona y les da sentido de identidad. En este tipo de sociedades en las que conviven diversas culturas, hay dificultades en la convivencia porque, generalmente, una de ellas es dominante y las demás son relegadas, con las consecuencias de desigualdad e injusticia económica y social para los ciudadanos que no se saben o no se sienten acogidos por la propia cultura.

En la ciudadanía nacional el Estado es una entidad culturalmente homogénea que desconoce la diversidad cultural de sus miembros y genera fragmentación social por las condiciones de desigualdad, cuando no se pertenece a la comunidad cultural hegemónica (Soysal, Baubock \& Bosniak, 2010). En lo jurídico, esta ciudadanía también rompe con el principio de igualdad política, porque limita los derechos y obligaciones fundamentales con los miembros que no comparten un conjunto de tradiciones, una lengua o unas creencias, entre otros.

La ciudadanía global o planetaria, parte del carácter multicultural de los Estados contemporáneos, y considera que estos se encuentran conformados por personas y colectividades cultualmente diversas (Kymlicka, 2003). En la ciudadanía global o planetaria, las diferencias culturales no son en sí mismas la causa de tensiones, hay otros factores como la migración creciente por inestabilidad política de los Estados, la pérdida de autonomía 
de los Estados contemporáneos derivada de la globalización, y el debilitamiento del Estado social, que traen consigo aumento de la desigualdad y la injusticia social en los Estadosnación, lo que implica que no pueden cumplir con la satisfación de las necesidades básicas de sus miembros (Soysal, Baubock \& Bosniak, 2010).

En este último concepto de ciudadanía, las diferencias culturales conllevan cambios en la concepción de diversidad, así:

- Cuando se acepta la convivencia de culturas diversas donde todos los miembros se sienten "ciudadanos de primera" (Cortina, 2009, p. 156), se habla de ciudadanía multicultural. En esta, la diversidad es un valor que invita al diálogo entre culturas diferentes que se respetan entre sí.

- Cuando los conflictos ocasionados por las diferencias derivadas de culturas distintas son una oportunidad de crecimiento personal y social, con aceptación y respeto por identidades culturales diversas que se enriquecen mutuamente en la convivencia, se habla de ciudadanía intercultural. En esta, la diversidad es la base del diálogo para la comprensión no solo de la propia cultura, sino también de otras, y para constuir conjuntamente nuevas perspectivas de convivencia.

En esencia, los conceptos anteriores de ciudadanía muestran que la diversidad es inherente a la sociedad y al proceso educativo. Sin embargo, diversos estudios (Felitti \& Rizzotti, 2018; Jimémez \& Goenechea, 2014; Molina \& Utges, 2011, entre otros) encuentran que la escuela permanece anclada en prácticas educativas que pretenden homogenizar pensamientos y actuaciones de los estudiantes, con el pretexto de formar en competencias de igualación de saberes desiguales, porque considera que la diversidad es un problema y no una oportunidad para construir sociedades democráticas incluyentes.

Según Dietz \& Mateos (2013), el problema anterior se origina en las "políticas de identidad" del Estado-nación, que enfoca la educación en el concepto de ciudadanía nacional, la cual homogeniza y trata de manera diferencial y discriminatoria a los grupos minoritarios, contradiciendo los principios básicos de la diversidad.

En la Educación para la Ciudadanía, Pagés (2007) y Gutiérrez, Arana \& Buitrago (2016), resaltan la necesidad de enseñar la diversidad desde el enfoque de la ciudadanía global o planetaria, para que los estudiantes comprendan la importancia del encuentro de sistemas de valores y costumbres diferentes, de grupos con creencias religiosas, hábitos y lenguas distintas, de manera que aprendan a convivir en la interacción entre lo local (lugar donde se nace o a donde se pertenece) y lo global.

En la Educación para la Ciudadanía global, la diversidad cultural alude a la pluralidad de culturas que coexisten en el mundo, que implica la preservación y promoción de las culturas existentes, el respeto hacia otras culturas y la convivencia solidaria entre ellas (UNESCO, 2015).

Cuando el propósito de la enseñanza de la diversidad está orientado a la formación de una ciudadanía global, esta se centra en el análisis de problemas o cuestiones sociales donde los estudiantes puedan establecer relaciones con sus vivencias y reflexionar sobre la realidad histórica, política, social y cultural. Al respecto, Dietz \& Mateos (2013) proponen 
una Pedagogía de la Diversidad basada en el análisis de situaciones relacionadas con la igualdad-desigualdad, la identidad-alteridad y la homogeneidad- heterogeneidad, para que los estudiantes comprendan la importanciade la justicia social y se comprometan con la construcción de sociedades democráticas.

Para Dietz y Mateos (2013), en la igualdad-desigualdad se pone en evidencia el análisis de las estructuras socioeconómicas imperantes en la sociedad, relacionadas con conflictos de clase y con las desventajas de los grupos denominados minoritarios.

La base de la igualdad es el respeto por los derechos humanos propios de la ciudadanía social, independientemente de la condición de edad, sexo, etnia, creencias y costumbres de las personas, tienendo presente que las desigualdades naturales y sociales reclaman igualaciones inherentes a la dignidad humana. Este es el segundo de los valores proclamados en la Revolución Francesa, que alude a (Cortina, 2009):

- La igualdad de todos los ciudadanos ante la ley.

- La igualdad de oportunidades, así como la compensación de desigualdades naturales y sociales.

- La igualdad de prestaciones sociales universalizadas por el Estado social.

En la identidad-alteridad se expresan, según Dietz \& Mateos (2013), las diferencias étnicas, culturales, de edad, género, orientación sexual y por discapacidades. Incluye el conocimiento que el sujeto tiene de la identidad propia, el reconocimiento de esta y la aceptación construída de ella desde los otros significados (Cortina, 2009). En el reconocimiento de la identidad es esencial la pertenencia a distintos grupos (por ejemplo, de mujeres negras, profesionales, cristianas, madres solteras, etc.), para optar libremente por identificarse, o no, con ellos. Para Cortina, la alteridad es un espacio entre lo personal y lo sociohistórico, donde se imagina al otro y se construye simbólicamente la identidad propia, preservando los espacios. En la homogeneidad-heterogeneidad se expresa el reconocimiento de la diversidad como característica esencial de la cultura. La heterogeneidad se relaciona con las particularidades específicas de las personas y los grupos sociales, teniendo en cuenta el carácter dinámico y cambiante de la cultura y de los seres que la conforman, mientras la homogeneidad se asocia con "similaridades entre los individuos" en formas de actuar, pensar, aprender, otras.

Las tres dimensiones propuestas para el estudio de la diversdad en el aula (Dietz \& Mateos, 2013), ponen de manifiesto su carácter complejo, porque en su análisis intervienen características individuales y sociales asociadas a diferentes formas de expresión e interacción de la diversidad lingüística, religiosa, étnica, sexual, entre otras, que muestran la importancia de conocer las concepciones de los estudiantes sobre estas, para facilitar y motivar el aprendizaje.

Investigaciones previas (Felitti \& Rizzotti, 2018; Molina \& Utges, 2011; Sagastizabal, San Martín, Perlo \& Pivvetta, 2009) concluyen que en el estudio de la diversidad deben incluirse las concepciones que los profesores y los estudiantes poseen sobre esta, para evitar perspectivas monoculturales como las que predominan en los libros de texto de ciencias 
sociales, que excluyen a las minorías étnicas, o que estimulan representaciones negativas de otras culturas para justificar determinados hechos sociales (por ejemplo, la colonización), buscando favorecer a un determinado grupo.

Según Molina, Mosquera, Utges, Mojica, Cifuentes, Reyes, Martínez \& Pedreos (2014), las investigaciones sobre concepciones de diversidad desde un enfoque educativo son pocas, pues el tema se aborda principalmente con enfoques biológico, médico o psicológico. En Educación, la investigación se ha enfocado principalmente en comprender las concepciones de diversidad de los docentes o de estudiantes universitarios.

En la enseñanza del conocimiento social es importante conocer las concepciones de diversidad, tanto de los profesores como de los estudiantes, porque ellas ponen de manifiesto los conocimientos arraigados en las personas, construidos en la interacción cotidiana y en los aprendizajes escolares previos. Según Pozo, Scheuer y Pérez (2006), las concepciones "inciden en lo que las personas hacen y expresan, en cómo enseñan, aprenden o interpretan su manera de aprender o las de los otros" (p. 55).

Para Pozo et al., las concepciones son explícitas e implícitas. Estas últimas son creencias adquiridas mediante procesos informales e inconscientes, su naturaleza es de carácter procedimental y poco reflexiva, "producto de la exposición reiterada e inconsciente a escenarios regulados por ciertos principios no articulados, igualmente implícitos” (2006, p. 48), conectados con las emociones y con respuestas viscerales, con las que las personas crean estereotipos sociales.

Las teorías explícitas, por el contrario, tienen un origen consciente, construido en el aprendizaje formal o académico mediante la reflexión de los saberes adquiridos. Es así como estas concepciones se enuncian principalmente por medio del lenguaje verbal, el “decir”, por tal motivo, su naturaleza es declarativa, a diferencia de las concepciones implícitas que se manifiestan a través del hacer.

Para que exista un cambio representacional en las concepciones implícitas de las personas, es importante volverlas conscientes, entender su naturaleza e identificarlas, para que puedan ser repensadas a través de procesos de educación formal, en los que la reflexión sobre la manera como se representa la realidad, ayude a su transformación en teorías explícitas.

En esencia, la enseñanza de temáticas como la diversidad a través de cuestiones controvertidas o de problemas sociales relevantes (situaciones de injusticia, discriminación, desigualdad, etc.), acerca el currrículo escolar a la vida de los estudiantes y facilita la explicitación de las concepciones de estos sobre el tema, para promover la reflexión del conocimiento, la formación de pensamiento crítico y la búsqueda de posibilidades de solución a situaciones de injusticia para la construcción de democracia social.

\section{METODOLOGÍA}

La investigación se fundamentó en los principios del enfoque interpretativo (Barton, 2006). El propósito fue identificar e interpretar las concepciones de diversidad en alumnos de educación básica primaria que estudian la diversidad a través del análisis de cuestiones sociales controvertidas. 
La estrategia empleada fue el estudio de casos (Yin, 2009), porque facilitó el acercamiento a las concepciones de diversidad de los estudiantes de manera holística, en contextos naturales que permitieron profundizar en la particularidad del fenómeno para comprender la realidad.

La selección de las instituciones educativas para la investigación se hizo a través de un muestreo por conveniencia (Hernández, Fernández \& Baptista, 2014), el interés se enfocó en elegir grupos con estudiantes provenientes de familias de distintas regiones de Colombia a la zona metropolitana de Pereira (Pereira \& Dosquebradas), por ser esta una región receptora de población en situación de riesgo social (Secretaría de Educación de Pereira, 2019). En total se eligieron tres grupos, uno de primero y dos de segundo de primaria, que suman 75 niños y niñas con edades entre los seis y los nueve años (Tabla 1).

Tabla 1. Número de instituciones educativas y grupos de estudiantes participantes en el estudio.

\begin{tabular}{ccccccc}
\hline \multirow{2}{*}{ Institución Educativa } & Carácter & Ciudad & Grado escolar & \multicolumn{3}{c}{ Número de estudiantes } \\
\cline { 3 - 7 } & & & Niños & niñas & total \\
\hline Institución $1^{1}$ & Privado & Dosquebradas & $2^{\circ}$ primaria & 12 & 11 & 23 \\
\hline Institución 2 & Público & Pereira & $1^{\circ}$ primaria & 9 & 11 & 20 \\
\hline Institución 3 & Público & Dosquebradas & $2^{\circ}$ primaria & 20 & 12 & 32 \\
\hline Total & & & 41 & 34 & 75 \\
\hline
\end{tabular}

Fuente: Elaboración propia con datos del corpus documental.

El procedimiento para la recolección y el análisis de información consta de tres momentos complementarios entre sí: el primero de preparación para la entrada a las aulas escolares, el segundo de recolección de información, y el tercero de análisis e interpretación de los datos.

En el primer momento, de preparación para la entrada a las aulas escolares, se seleccionaron las instituciones educativas y se presentó el proyecto a los profesores de básica primaria, para que decidieran de manera voluntaria la participación en el estudio. Con la aceptación de tres profesores, se procedió a explicar el proyecto a los adultos responsables de los estudiantes en cada uno de los grupos, por ser estos menores de edad, así como a los niños y las niñas para solicitarles posteriormente firmar el consentimiento informado a todos.

En el primer momento también se elaboró y se validó el cuestionario sobre concepciones de diversidad, que consta de ocho preguntas tipo escala Likert (Hernández et al. 2014), en el que se presentan situaciones relacionadas con las dimensiones de la diversidad propuestas por Dietz \& Mateos (2013), de igualdad-desigualdad social, homogeneidad-heterogeneidad, y alteridadidentidad, porque cubren de manera amplia la complejidad de la temática, para que los estudiantes elijieran la opción de respuesta que consideraran más adecuada (siempre, a veces o nunca).

La preparación para entrar al campo terminó con los acuerdos realizados con cada profesora sobre la planeación y el desarrollo de unidades didácticas, para enseñar la diversidad a partir del análisis de cuestiones o de problemas socialmente relevantes, en los que los estudiantes pudieran dialogar, debatir sobre el tema e interactuar de manera natural durante la práctica educativa.

1 En adelante la institución 1 corresponde al caso 1, la institución 2 al caso 2 y la institución 3, al caso 3. 
El segundo momento, de recolección de información, inicia con la aplicación del cuestionario sobre concepciones de diversidad a cada uno de los estudiantes, por parte de las profesoras titulares, a quienes se les explicó previamente el procedimiento a seguir. Posteriormente, se observó en cada aula de clase el desarrollo de las unidades didácticas desplegadas por las docentes con sus estudiantes. Según las planeaciones docentes, el objetivo de las prácticas fue: buscar que los estudiantes comprendan la importancia de la diversidad, aprendan a respetar las diferencias y a compartir con otras culturas o grupos culturales.

Durante el desarrollo de las prácticas educativas, los estudiantes hicieron folders o portafolios con dibujos y actividades, que fueron recogidos como parte del registro documental para la investigación.

Finalizadas las unidades didácticas, se organizó el corpus documental con toda la información recogida para el análisis de la información, en el tercer momento, que comprendió tres fases complementarias: el análisis de los cuestionarios de los estudiantes de los tres grupos, y de las prácticas educativas en dos casos de grado segundo de primaria. El caso de primero de primaria se descartó porque la profesora no tuvo en cuenta la planeación en el desarrollo de la unidad didáctica, que terminó siendo una clase convencional, con actividades tomadas de libros de texto. El análisis terminó con la triangulación de la información de los casos analizados en las fases anteriores, para dar cuenta del propósito del estudio de identificar e interpretar las concepciones de diversidad de los estudiantes en prácticas de enseñanza de la Educación para la Ciudadanía.

Las técnicas para el análisis de la información en cada fase fueron las siguientes: en la primera fase, los cuestionarios se procesaron a través de análisis de frecuencias, la información se agrupó por preguntas en dimensiones (igualdad-desigualdad, homogeneidadheterogeneidad e identidad-alteridad), y con los resultados de cada dimensión se analizaron tendencias en los tres grupos de estudiantes.

En la segunda fase, la identificación de las concepciones de diversidad que emergen en cada uno de los grupos durante las prácticas educativas se hizo a través de la codificación teórica, que consta de tres momentos (Strauss \& Corbin, 2002): la codificación abierta para identificar y etiquetar los datos relacionados con el fenómeno analizado, la codificación axial para agrupar y categorizar los datos con sus conceptos y características, y la codificación selectiva para analizar los datos categorizados y dar cuenta de las concepciones de diversidad de los estudiantes en cada una de las prácticas educativas.

En la tercera y última fase del análisis, la identificación e interpretación de las concepciones de diversidad de los estudiantes, se hizo a través de la triangulación mixta (Flick, 2014), que consiste en analizar los resultados que convergen, divergen y complementan en los casos estudiados, para dar validez al estudio y profundizar, detallar o explicar lo que los estudiantes piensan, dicen y/o hacen con relación a la diversidad.

\section{RESULTADOS}

Los resultados del análisis descrito en el apartado anterior, se presentan a continuación en el siguiente orden: primero, los resultados del cuestionario aplicado antes de la práctica 
educativa a cada grupo de estudiantes. Segundo, la identificación de las concepciones de diversidad en cada una de las prácticas educativas. Y, tercero, los resultados de la triangulación del análisis de los dos momentos anteriores, con las concepciones de diversidad de los alumnos de educación básica que hacieron parte del estudio.

\section{Concepciones de diversidad identificadas en cada grupo de estudiantes antes de la práctica educativa}

Las concepciones de diversidad de los estudiantes identificadas antes de la práctica educativa, son el resultado de la aplicación del cuestionario, instrumento que fue procesado a través de análisis de frecuencias, agrupando los enunciados por dimensiones (identidadalteridad, homogeneidad-alteridad e igualdad-desigualdad), con las opciones de respuesta seleccionadas por los estudiantes en cada una de ellas (siempre, a veces, nunca) (Tabla 2).

Tabla 2. Resultados del cuestionario sobre concepciones de diversidad de los estudiantes de tres instituciones educativas.

\begin{tabular}{|c|c|c|c|c|c|c|c|c|c|c|}
\hline \multirow[b]{2}{*}{ 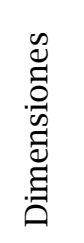 } & \multirow[b]{2}{*}{ 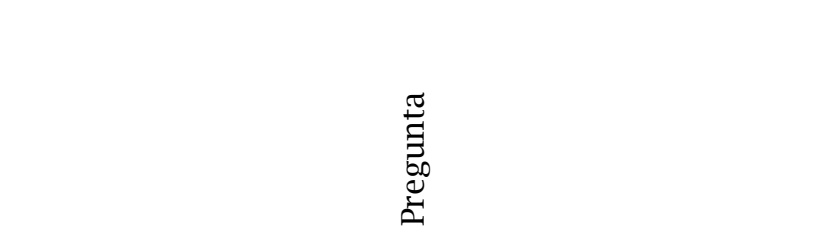 } & \multicolumn{3}{|c|}{ Institución 1} & \multicolumn{3}{|c|}{ Institución 2} & \multicolumn{3}{|c|}{ Institución 3} \\
\hline & & do & 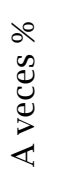 & 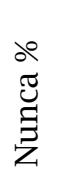 & 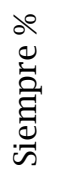 & 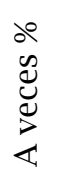 & 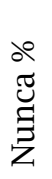 & 赵 & 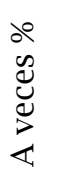 & 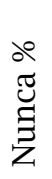 \\
\hline \multirow{2}{*}{ 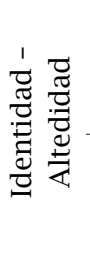 } & $\begin{array}{l}\text { En el barrio La Isabela algunos vecinos tienen problemas } \\
\text { entre ellos. ¿Crees que estos se deben a sus costumbres, } \\
\text { creencias religiosas o a la procedencia de alguno de ellos? }\end{array}$ & 9 & 70 & 21 & 70 & 15 & 15 & 28 & 51 & 21 \\
\hline & $\begin{array}{l}\text { Si te encuentras en La Isabela con un niño o niña de color } \\
\text { de piel diferente a la tuya que te hace un gesto extraño o } \\
\text { expresa palabras desconocidas para ti, ¿te sentirías ofendido? }\end{array}$ & 30 & 35 & 35 & 30 & 25 & 45 & 45 & 34 & 21 \\
\hline \multirow{3}{*}{ 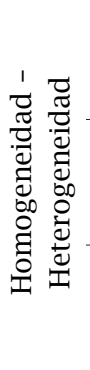 } & $\begin{array}{l}\text { Si te invitaran a jugar los niños del barrio, ¿preferirías que tu } \\
\text { equipo estuviera conformado por niñas o niñas que tengan } \\
\text { tu mismo color de piel o que sean de tu mismo sexo? }\end{array}$ & 26 & 48 & 26 & 40 & 20 & 40 & 28 & 31 & 41 \\
\hline & $\begin{array}{l}\text { En La Isabela viven muchas personas, ¿te juntarías con } \\
\text { personas de otros grupos, creencias religiosas, o que } \\
\text { hablen distinto a ti? }\end{array}$ & 22 & 43 & 35 & 70 & 30 & 0 & 59 & 17 & 24 \\
\hline & $\begin{array}{l}\text { Cuando llegan personas de otros lugares a tu barrio, } \\
\text { preguntas sobre sus costumbres, formas de hablar, o de } \\
\text { vestir para juntarte con ellos. }\end{array}$ & 17 & 26 & 57 & 0 & 0 & 0 & 35 & 31 & 34 \\
\hline \multirow{3}{*}{ 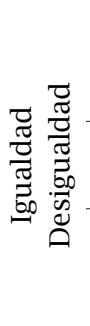 } & $\begin{array}{l}\text { Sí vas caminando por el barrio La Isabela y te encuentras a } \\
\text { un niño en problemas, ¿lo ayudarías sin importar su aspecto } \\
\text { físico, su forma de hablar o el lugar de donde proviene? }\end{array}$ & 74 & 9 & 17 & 70 & 30 & 0 & 62 & 24 & 14 \\
\hline & $\begin{array}{l}\text { Si fueras el líder del barrio La Isabela, ¿permitirías que } \\
\text { personas distintas a ti vivieran ahí? }\end{array}$ & 57 & 26 & 17 & 0 & 0 & 0 & 55 & 28 & 17 \\
\hline & $\begin{array}{l}\text { Al momento de juntarte o de jugar con otros, ¿te fijas en } \\
\text { la forma en la que visten, hablan, el lugar donde viven o si } \\
\text { es un niño o una niña? }\end{array}$ & 26 & 39 & 35 & 60 & 5 & 35 & 24 & 35 & 41 \\
\hline
\end{tabular}

Fuente: Cuestionarios aplicados a los estudiantes de los casos del estudio. 
De acuerdo con los resultados de la Tabla 2, en la dimensión de identidad - alteridad se agrupan los enunciados que expresan el reconocimiento de los estudiantes de la identidad propia y la pertenencia e identificación o no, con otros grupos, con las siguientes respuestas en cada uno de los grupos encuestados (Fig. 1).

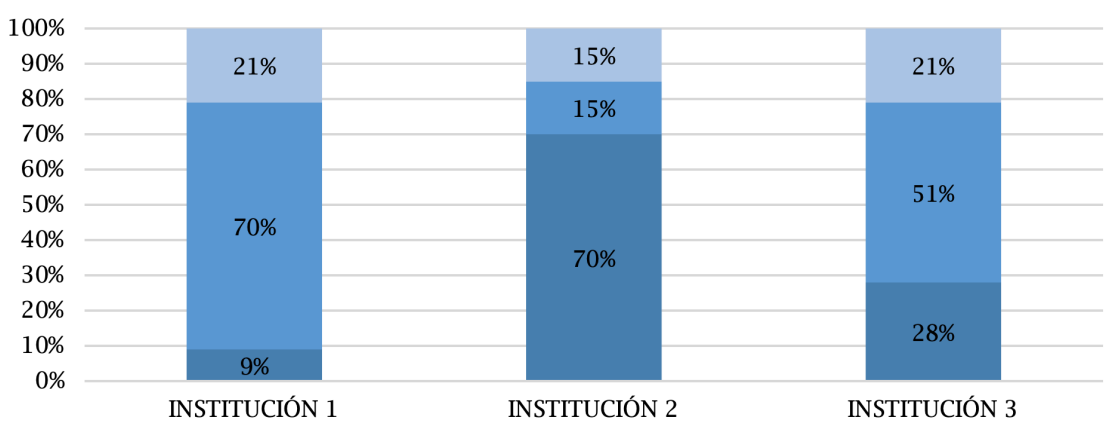

1. En el barrio Santa Isabel algunos vecinos tienen problemas. Crees que estos problemas se deben a sus costumbres, religiones, o diferencias.

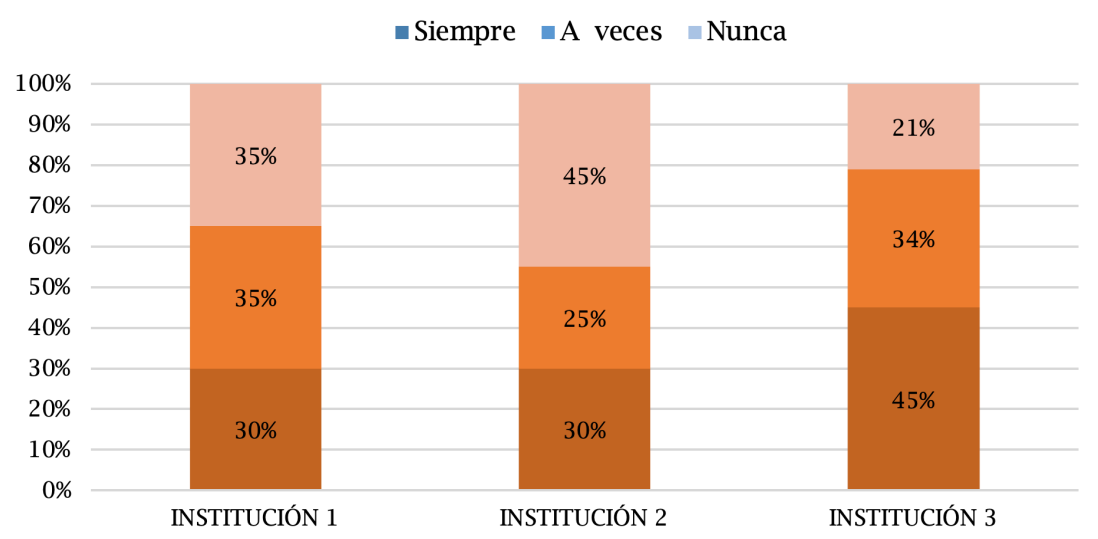

2. Si te encuentras en Santa Isabel con un niño o niña de color de piel diferente a la tuya, realiza un gesto extraño o expresa palabras desconocidas para ti, te sentirías ofendido.

$\square$ Siempre $\backsim$ A veces Nunca

Fig. 1. Resultados de las preguntas asociadas a la dimensión de identidad-alteridad en los tres grupos de estudiantes.

Fuente: Elaboración propia a partir de los datos de la Tabla 2.

En el enunciado 1, relacionado con problemas entre vecinos por distintas causas, en 2 instituciones entre el $50 \%$ y el $70 \%$ de los estudiantes considera que a veces estos se deben a diferencias en costumbres, creencias religiosas o a la procedencia de uno de ellos. Por el contrario, en la institución 2 el 70\% de los estudiantes considera que los problemas con los vecinos siempre se deben a aquellas diferencias.

En el enunciado 2, sobre la aceptación o el rechazo a otros niños o niñas por formas de expresión o por comportamientos culturales propios, el 30\% para el caso de 2 instituciones, en tanto que en una institución $45 \%$ de los estudiantes manifiesta que siempre se sentiría 
ofendido si un niño o niña que no conoce le hace un gesto desconocido. Entre el 34 y 35\% para el caso de 2 instituciones y, el 25\% en una institución, menciona que a veces se sentiría ofendido. Y, entre el 35\% y el $45 \%$ de los estudiantes en 2 instituciones informa que no se sentiría ofendido si sucediera esta situación, contrario a un $21 \%$ de los estudiantes en una institución que dice que no se sentiría ofendido.

En síntesis, para los estudiantes, circunstancias como el color de piel, las expresiones o costumbres de otras personas puede producir problemas o conflictos en un grupo o comunidad.

En la dimensión de homogeneidad - heterogeneidad se agruparon los enunciados que expresan particularidades de las personas y los grupos sociales en formas de actuar, pensar, aprender, entre otras características esenciales de la cultura, con las siguientes respuestas en cada uno de los grupos encuestados (Fig. 2).

De acuerdo con los resultados del enunciado 3, las preferencias en la conformación de grupos de juego con base en semejanzas o diferencias en características físicas o culturales, en 2 instituciones entre el $26 \%$ y el $28 \%$ de los estudiantes manifiesta que siempre prefiere jugar en equipos conformados por niños o niñas del mismo color de piel, o del mismo sexo, contrario a 1 institución en la que el 40\% de los estudiantes tiene esta prefernecia. En las 3 instituciones el 20\%, el $48 \%$ y el $31 \%$ considera que a veces conforma grupos de juego teniendo en cuenta características como las mencionadas. Y, el 26\% para el caso de 1 institución, en tanto que el $40 \%$ y $41 \%$ para el caso de 2 instituciones, los estudiantes afirma que nunca se fija en el color de piel, el sexo o la apariencia de los otros niños para jugar con ellos.

En la expresión 4, sobre la relación con personas del barrio independientemente de sus características, entre el 59\% y el 70\% de los estudiantes de dos instituciones responde que siempre se junta con personas con creencias o costumbres diferentes a ellos, mientras que en la otra institución, el $22 \%$ de los encuestados manifiesta que siempre lo hace. De igual manera, reséctivamente el 35\%, 30\% y el 24\% de los estudiantes de las tres instituciones plantea que nunca tendría una interacción con personas diferentes a ellos.

En el enunciado 5, relacionado con la identificación previa de las personas para conocer su procedencia antes de relacionarse con ellas, entre el $17 \%$ y el $34 \%$ de los estudiantes considera que al llegar personas nuevas al barrio siempre pregunta por las costumbres o las formas de hablar antes de interactuar socialmente con ellas. Asimismo, entre el $34 \%$ y el $54 \%$ de los encuestados manifiesta que nunca preguntaría sobre estos aspectos para entablar contacto con otras personas.

En síntesis, en la dimensión relacionada con homogeneidad - heterogeneidad se identifica una mayor tendencia a la aceptación de las particularidades de las personas y los grupos sociales para el establecimiento de relaciones con ellos.

En la dimensión de igualdad-desigualdad, se agruparon las afirmaciones afines al reconocimiento de los derechos humanos propios de la ciudadanía social, independientemente de la condición de edad, sexo, etnia, creencias y costumbres de las personas o los grupos sociales, con las siguientes respuestas en cada uno de los grupos encuestados (Fig. 3).

En el enunciado 6, relacionado con el apoyo y la solidaridad humana independientemente de la condición social de las personas, en 2 instituciones entre el $70 \%$ y el $74 \%$, en tanto que 
en una institución el 62\% de los estudiantes expresa que siempre ayudaría a un niño en problemas sin importar su aspecto, color de piel, o costumbres. Solo entre el $14 \%$ y el $17 \%$ de los encuestados, afirma que nunca lo haría.

En la afirmación 7, vinculada con las relaciones de igualdad o desigualdad social por condiciones de vulnerabilidad o por la pertenencia a grupos denominados minoritarios, entre el $55 \%$ y el $57 \%$ de los estudiantes manifiesta que si ellos fuesen los líderes del barrio siempre permitirían a personas con características o condiciones diferentes a ellos. Entre el 26\% y 28\% plantea que solo lo permitiría algunas veces, y el 17\% de los encuestados expresa que nunca lo permitiría.

En el ítem siete no hay datos del caso 2 , porque la profesora titular del grupo no lo tuvo en cuenta por considerar que los estudiantes no tienen la capacidad de analizar este tipo de afirmaciones, debido a la edad y al nivel escolar (primero de primaria).

En el enunciado 8, sobre las relaciones entre las personas sin importar su procedencia, la condición biológica o social, en uno de los grupos encuestados, el 60\% de los estudiantes informa que siempre se fija en la forma de vestir, de hablar o en el lugar de donde provienen las personas con quienes interactúan, mientras en los otros dos grupos, entre el 24\% y el 26\% de los encuestados responde que nunca se fija en la condición de las personas para relacionarse con ellas.

En síntesis, en la dimensión de igualdad-desigualdad se muestra mayor tendencia en las respuestas relacionadas con el reconocimiento de los derechos sociales de las personas, donde priman las relaciones basadas en el respeto y la solidaridad humana, sobre la condición social.

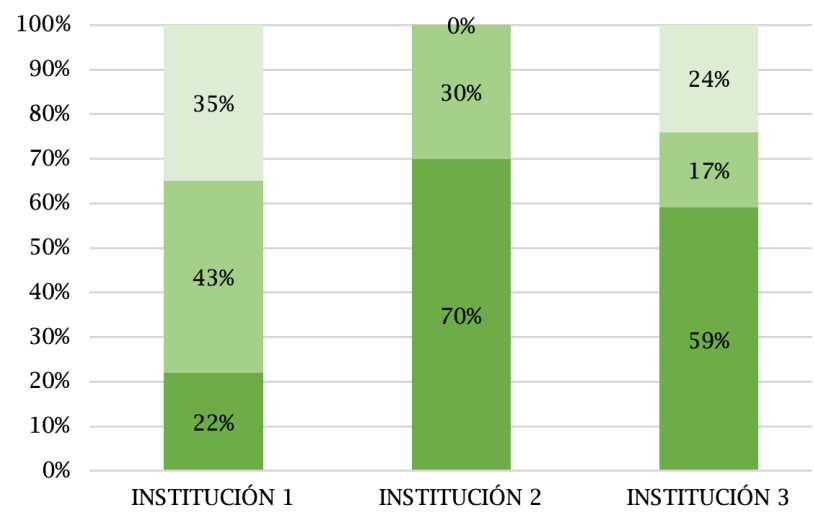

4. En Santa Isabel viven muchas personas, te juntarías con personas de otros grupos, religiones, o que hablen distinto a ti.

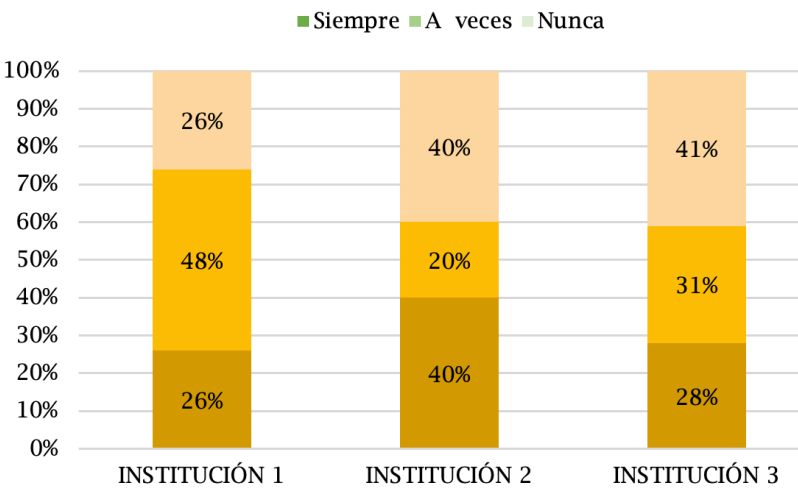

3. Si te invitaran a jugar los niños del barrio, preferirías que tu equipo estuviera formado por niñas o niños que tengan tú mismo color de piel o que sean de tu mismo sexo.

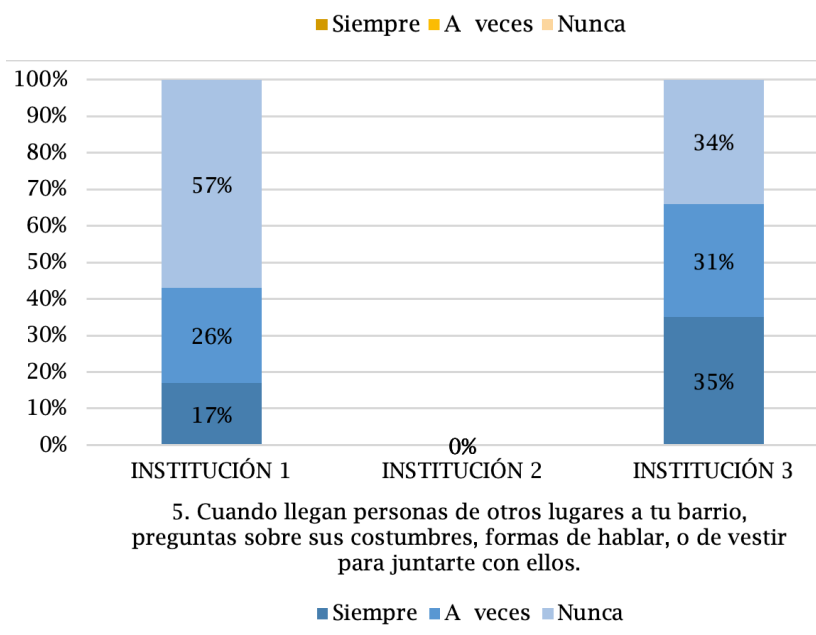

Fig. 2. Resultados de las preguntas asociadas a la dimensión de homogeneidad-heterogeneidad en los tres grupos de estudiantes.

Fuente: Elaboración propia a partir de los datos de la Tabla 2. 


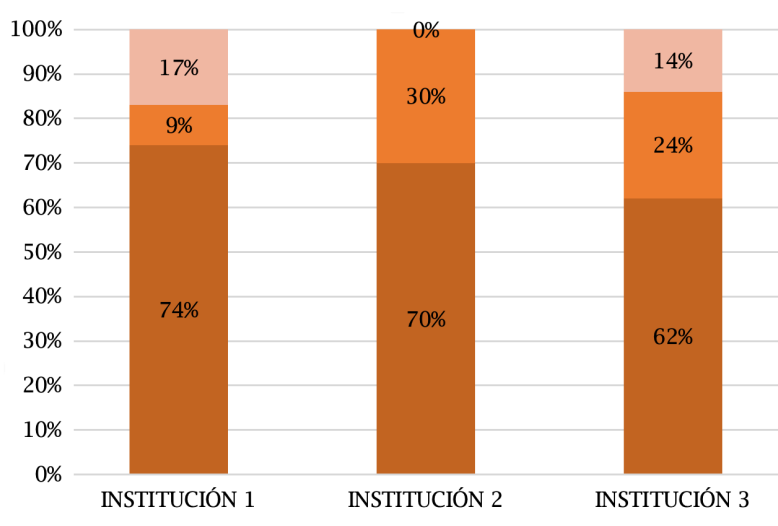

6. Sí vas caminando por el barrio Santa Isabel y te encuentras un niño en problemas, lo ayudarías sin importar el color de su piel,

su aspecto, religión o el lugar de donde vienen.

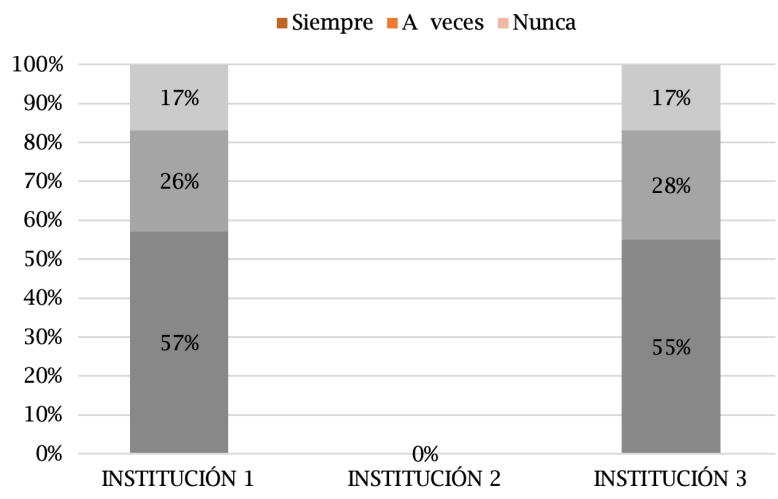

7. Si fueras el líder del barrio Santa Isabel, permitirías que personas distintas a ti vivieran ahí.

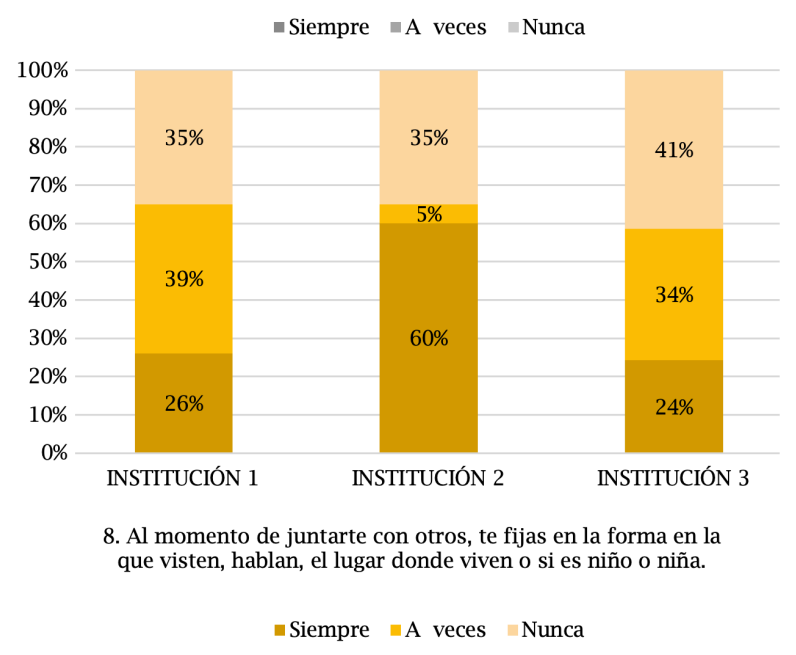

Fig. 3. Resultados de las preguntas

asociadas a la dimensión igualdad-desigualdad en los tres grupos de estudiantes. Fuente: Elaboración propia a partir de los datos de la Tabla 2.
En los resultados del análisis de las tres dimensiones anteriores se encuentra que, aunque en todos los enunciados del cuestionario hay porcentajes en las distintas opciones de respuesta, en general, hay mayor tendenciaenlas relacionadasconlaaceptación de las particularidades de las personas y los grupos sociales, independientemente de su condición biológica o cultural para el establecimiento de relaciones con otros. De acuerdo con la propuesta de Dietz (2013), un porcentaje mayor de estudiantes se identifica con situaciones de igualdad, heterogeneidad y alteridad.

\section{Concepciones de diversidad identificadas en las prácticas educativas}

Para este momento del análisis se seleccionaron dos prácticas educativas por la siguiente razón: una de las profesoras desarrolló la unidad didáctica con base en actividades tomadas de libros de texto, en las que los estudiantes tienen pocas opciones de debatir y dialogar sobre el tema, lo cual dificulta la explicitación de las concepciones de los niños y las niñas sobre la diversidad. Se trata de la misma profesora que omitió uno de los enunciados del cuestionario inicial realizado a los estudiantes, por tal razón, en adelante este caso es descartado.

En los casos seleccionados, el uno corresponde a una institución privada financiada por una empresa grande de Colombia cercana a la institución educativa, con estudiantes que provienen principalmente de una comunidad con población en situación de riesgo social. El caso dos corresponde a un grupo de estudiantes de una institución pública que también alberga población en situación de vulnerabilidad social. 


\section{Concepciones de diversidad que emergen durante la práctica educativa en el caso 1}

La unidad didáctica en la que se analizaron las concepciones de diversidad de los estudiantes, partió de un caso presentado por la profesora a través de un video, con una situación de discriminación de una niña que llega a una institución educativa de otra región del país, por motivos laborales de los padres, y se enfrenta a burlas permanentes de los compañeros por su color de piel y su manera de actuar. A través del caso, la profesora desarrolló durante ocho sesiones de hora y media aproximadamente, cada una, actividades individuales, en pequeños grupos y en el gran grupo, guiadas por preguntas relacionadas con la diversidad, para que los estudiantes propusieran soluciones viables frente a situaciones de discriminación.

La identificación y el análisis de las concepciones de diversidad en el caso descrito previamente, se hizo a través de la codificación teórica Flick (2012, p. 193), en la que emerge en la codificación axial la siguiente categoría, con los conceptos y características que se sintetizan a continuación (Fig. 4).

De acuerdo con los datos de la Fig. 1, la categoría que emerge durante la práctica educativa se denomina: 'reconocimiento de diferencias y contradicciones entre lo dicho y lo hecho, que expresa la identificación de diferencias biológicas y culturales en el decir, así como manifestaciones de discriminación o rechazo en la interacción entre estudiantes.

En las diferencias biológicas los estudiantes manifiestaron que, como seres humanos semejantes, hay características y aspectos que hacen a cada persona diferente de las otras, por el 'tono de piel', 'el sexo', 'entre otros'. Ejemplo, el E9 expresa: E8 'es trigueña', 'trigueña', 'trigueña y yo soy blanca' (sesión 1$)^{2}$.

En lo cultural, los estudiantes expresan que las diferencias entre ellos se relacionan con el lugar de procedencia y con las prácticas sociales por creencias religiosas, gustos musicales, entre otros. Ejemplo: el E20 manifiesta: 'yo soy cristiano'. E4: 'yo soy católica', 'y estoy haciendo catequesis'. E8 dice: 'yo también' [se escuchan varias voces expresando lo mismo] (sesión 5).

En el desarrollo de las distintas actividades relacionadas con la unidad didáctica, se identificaron acciones de rechazo, burlas, maltrato con algunos de los estudiantes, que se expresaron con gestos, empujones, ocultamiento de pertenencias de los compañeros, gritos y críticas. Ejemplo: E15 dice: ' ...imaginen que ustedes son Sofía' (niña del caso de discriminación), ‘cómo se sentirían?'.E3: 'oigan a este, iyo no tengo pelo chusco, de negra!' [frunce el ceño]. E15: 'por eso dije, cómo se imaginarían...' [alza las cejas] (sesión 6).

En síntesis, durante el desarrollo de la unidad didáctica del caso 1, se encuentra que, por una parte, los estudiantes reconocen las semejanzas como seres humanos y la existencia de diferencias en las personas y entre ellos mismos, por la condición biológica o por prácticas culturales distintas, que aluden al reconocimiento de la alteridad (Cortina, 2009). Y, por otra parte, los niños y niñas expresan acciones de rechazo y discriminación

2 E8 corresponde al código con el que se identificó a los estudiantes. S corresponde a la sesión en la que se identifica el ejemplo. C1 o C2 corresponde al caso. P corresponde a la profesora. 
PARADOJAS ENTRE EL DECIR Y EL HACER ACERCA DE LA DIVERSIDAD

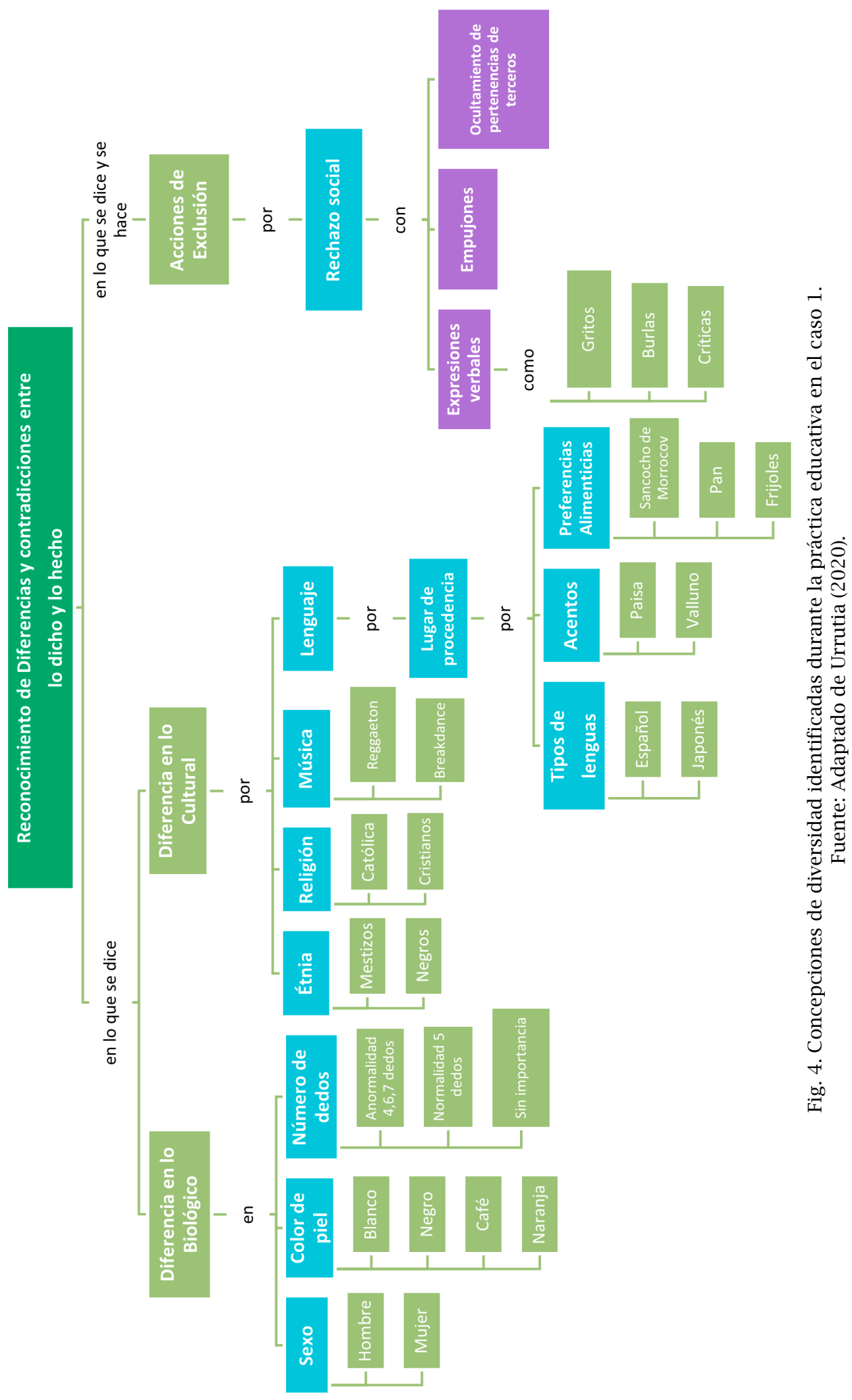


con algunos compañeros, por las mismas razones anteriores, lo cual contradice el concepto anterior en el que expresan respeto por las diferencias (étnicas, culturales, de género).

Concepciones de diversidad que emergen durante la práctica educativa en el caso 2

La unidad didáctica en la que se analizaron las concepciones de diversidad de los estudiantes del caso 2, inició con la identificación de situaciones de discriminación de niños en los contextos cercanos a la vida de los estudiantes, por distintas causas derivadas de la pobreza y carencias en las necesidades básicas. A partir de las problemáticas anteriores, la profesora orientó durante 6 sesiones de hora y media, aproximadamente, cada una, actividades individuales y en pequeños grupos, que de acuerdo con la planeación inicial, tuvieron como objetivo que los niños y las niñas comprendieran la importancia de la diversidad y aprendieran a interactuar con otros en la vida social.

La identificación y el análisis de las concepciones de diversidad en el desarrollo de la unidad didáctica descrita, se hizo de igual manera que en el caso anterior, a través de la codificación teórica (Flick, 2012), en la que emergió la siguiente categoría con los conceptos y características que se sintetizan a continuación (Fig. 5).

De acuerdo con los datos de la Fig. 2, la categoría emergente en el análisis de la práctica educativa se denomina, 'paradojas entre el decir y el hacer sobre la diversidad', con tres grupos de conceptos relacionados con el decir: el reconocimiento de semejanzas, de diferencias y soluciones a la discriminación. Y, un cuarto concepto sobre el hacer, acerca de la diversidad.

En lo que dicen los estudiantes sobre la diversidad, se identifica el reconocimiento de semejanzas en aspectos biológicos y sociales de las personas. En lo biológico, los niños expresan que, como personas, somos iguales físicamente y con necesidades básicas comunes e irremplazables, como comer o dormir, sin importar el lugar de procedencia o la apariencia física. Ejemplo: E10: 'nos parecemos en que somos personas y a todos nos gusta comer' (sesión1).

En lo social, para los estudiantes, la composición familiar es común a todos independientemente de donde vivan. Ejemplo: E3 dice: 'nos parecemos en la familia, yo tengo una familia grande, con mi papá, mi mamá y muchos tíos y primos, y Jerónimo también' (sesión 3).

En las expresiones relacionadas con el decir, los estudiantes también identifican diferencias en aspectos biológicos y culturales. En lo biológico, expresan características relacionadas con aspectos físicos como la forma del cabello (crespo o lacio) y con el sexo. Ejemplo: E1 expresa: 'somos diferentes porque algunos son niños y otras son niñas' (sesión 3).

En lo cultural, los estudiantes establecen diferencias asociadas con las etnias, el lugar de procedencia geográfica, las creencias religiosas, las costumbres alimenticias y, en el intelecto, (consideran a los chinos más inteligentes porque producen tecnología). Ejemplo: E20: ‘yo creo que es negrita porque es de Cali’ (sesión 1). 
PARADOJAS ENTRE EL DECIR Y EL HACER ACERCA DE LA DIVERSIDAD

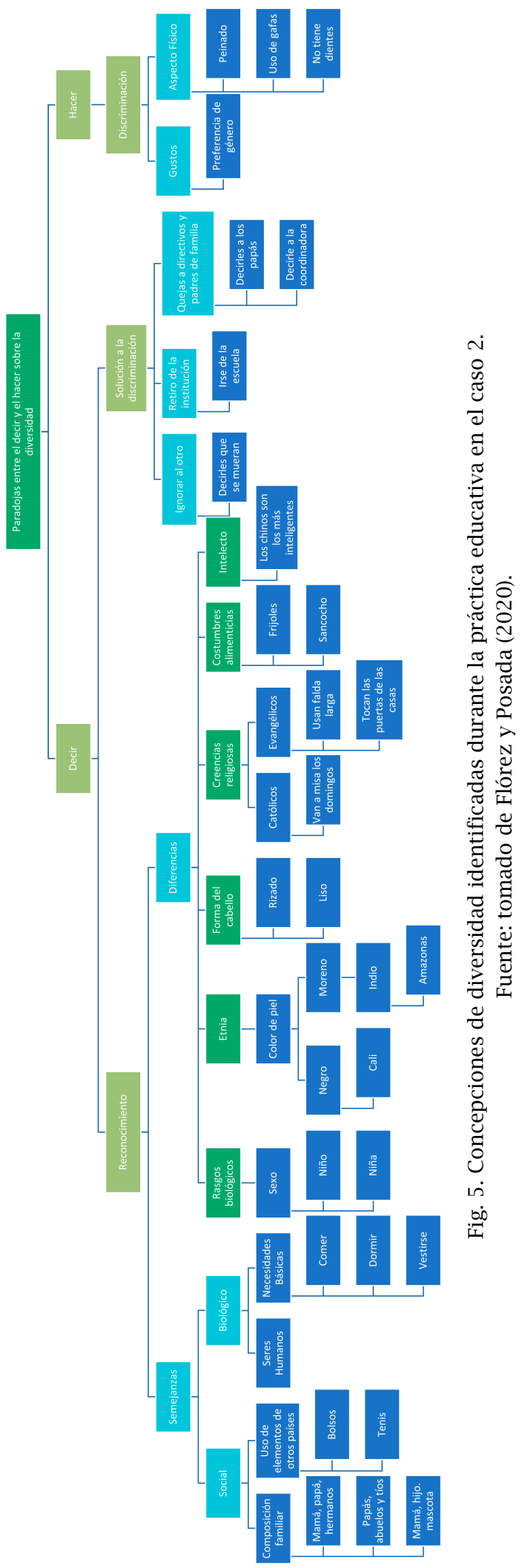


También desde el decir, los estudiantes proponen soluciones a la discriminación, como la evasión, la evitación, la eliminación del que causa conflictos, o la delegación de la solución de estos en personas consideradas por ellos como figuras de autoridad (profesores, papás o mamás). Ejemplos:

E30: ‘yo le quiero decir a Sofía que los mire y que les diga que se mueran’.

E10: 'yo creo que es mejor no ponerle cuidado a los niños que lo molestan a uno'.

E2: 'Yo preferiría mejor irme de la escuela'.

E22: 'Decirle a la coordinadora o a la profesora'.

E31: 'Yo, decirles a mis papás para que saquen a esos niños de la escuela' (sesión 6).

En las acciones y comportamientos relacionados con la diversidad identificados durante la práctica educativa, los niños y la niñas se burlaron de los compañeros por el aspecto físico o por las preferencias deportivas, también rechazan a los compañeros por distintos motivos (cansones, oler feo, color de piel). Ejemplo:

E15: 'No quiero trabajar con ese grupo porque me están molestando’.

P: ‘Por qué?, ¿qué le están haciendo?’

E15: 'me están diciendo gafufo, cuatro lámparas, y se ríen de mí’ (sesión 5).

En síntesis, en el caso se refleja discrepancia entre el reconocimiento verbal de semejanzas y diferencias de tipo biológico y cultural entre la personas (reconocimiento de la heterogeneidad), y lo que los estudiantes expresan como solución a situaciones de discriminación, así como en las distintas manifestaciones de rechazo, segregación y burla a algunos de sus compañeros por características derivadas del aspecto físico, el género, o por sus tradiciones culturales, las cuales se relacionan con el desconocimiento de las particularidades de las personas y los grupos sociales.

\section{Concepciones de diversidad en los estudiantes participantes en el estudio}

En este último momento, se analizaron e interpretaron las concepciones de diversidad de los estudiantes, con base en los resultados parciales del análisis de los dos casos que conforman la unidad de análisis del estudio (caso 1 y caso 2). Con apoyo de la triangulación mixta (Flick, 2014), se identificaron semejanzas, diferencias y complementariedad entre lo que los estudiantes piensan, dicen y hacen acerca de la diversidad, con los siguientes resultados.

En las expresiones verbales de los estudiantes acerca de la diversidad, manifestadas en los cuestionarios iniciales y en distintos momentos de las prácticas educativas, se encuentran las siguientes semejanzas:

- El reconocimiento del carácter humano de las personas independientemente de su condición biológica y cultural, que da cuenta de la igualdad de todos los ciudadanos ante 
la ley (Cortina, 2009), y de la comprensión de los derechos humanos relacionados con la ciudadanía social, como se observa en el siguiente ejemplo de E19: 'nos parecemos en que somos personas con derechos y deberes' (caso 2).

- El conocimiento que los estudiantes tienen de las distintas tradiciones, creencias religiosas, lengua, gustos musicales, ente otros, que hay entre ellos, las cuales evidencian la identificación de particularidades culturales referentes a la heterogeneidad como característica esencial de la cultura. Ejemplo: E7 expresa: 'en Venezuela tenemos costumbres muy arraigadas, en semana santa comemos pastel de morrocoy y hayacas, ustedes comen sardinas y pescado' (caso 1).

- La similitud identificada en los cuestionarios sobre la tendencia de los estudiantes al reconocimiento de la igualdad, la solidaridad, la alteridad, entre otras, y distintos tipos de expresiones verbales de estos en el transcurso de las unidades didácticas, que aluden al respeto por los compañeros y a la importancia de ayudar a quienes lo necesitan, sin importar sus rasgos físicos, las creencias o los gustos musicales. Las expresiones anteriores muestran la aceptación de los niños y las niñas de la diversidad humana, como se observa en el siguiente ejemplo tomado del caso 2: 'Si ella es morena y tiene pecas es porque su familia tiene pecas, y eso no importa, somos amigos' (E18, sesión 3).

Las expresiones anteriores en las que los estudiantes reconocen la heterogeneidad, la alteridad, la igualdad y la solidaridad humana, así como la tendencia en las respuestas de los cuestionarios a la aceptación y el reconocimiento de la diversidad, entran en contradicción con distintos tipos de acciones y comportamientos de estos, en los que manifiestan rechazo y discriminación con algunos de los compañeros por la identidad de género, la procedencia geográfica o por el color de la piel, entre otras características.

El siguiente ejemplo tomado del caso 2, testifica el rechazo y la discriminación a los compañeros: la profesora solicita conformar grupos pequeños para realizar una actividad y queda una estudiante sin grupo de trabajo. Ella pide a la estudiante vincularse a un grupo X, e inmediatamente se le acerca E19 para expresarle en voz baja que a ellas no les gusta trabajar con la compañera, porque: 'profe es que ella parece un niño y solo le gusta jugar con E24 y E26'. (sesión 2).

El ejemplo anterior testifica las diferencias entre las concepciones explícitas (el decir) acerca de la diversidad, y lo que los estudiantes hacen durante la interacción en el aula, cuando discriminan a los compañeros, lo cual expresa sus concepciones implícitas sobre la diversidad.

Durante ambas prácticas educativas también se identificaron propuestas de solución a situaciones de discriminación, en las que los estudiantes propusieron el rechazo hacia las personas que causan problemas, la evasión de situaciones de conflicto o la delegación de la solución de estos en figuras de autoridad (papás, maestros, policías).

Las expresiones anteriores pueden asimilarse con acciones y expresiones de discriminación de los niños y las niñas con algunos de los compañeros por sus características físicas, la identidad de género o por la procedencia cultural. Ejemplo: durante una actividad 
grupal, E8 menciona al oído de la docente que no quiere realizar trabajos en grupo con E18, pero sí con E21. Ella le pregunta la razón, y el niño responde: 'el E18 nunca hace nada y no me gusta estar con él' (caso 1, sesión 6).

En las expresiones y ejemplos anteriores de rechazo o de discriminación de los compañeros se encuentra una clara relación con los denominados estereotipos sociales, que son "creencias compartidas acerca de un conjunto de características que se atribuyen a un grupo humano” (Jiménez y Goenechea, 2014, p. 129). Debido a los estereotipos, los niños estigmatizan a sus compañeros por el tono de la piel ('es negro porque es del Choco' [región colombiana con la mayoría de población afrodescendiente]) (E31, caso 1); o por la condición de género ('las mujeres que juegan fútbol no son femeninas') (E19, caso 2).

En el desarrollo de las prácticas educativas también se identificaron expresiones relacionadas con prejuicios sociales, que son predisposiciones favorables o desfavorables hacia personas o grupos sociales sin tener elementos de juicio (Jiménez \& Goenechea, 2014, p. 130). En los prejuicios, se reconocieron expresiones en las que los estudiantes discriminan a otros grupos o al propio grupo. Ejemplo: E8 dice: 'profe, los chinos son más inteligentes, hicieron los teléfonos celulares, los computadores y las Tablet' (caso 1).

Los resultados anteriores evidencian que, en las expresiones verbales, los estudiantes reconocen la diversidad como manifestación de pluralidad cultural, las cuales se relacionan con teorías explícitas de construcción del conocimiento social, que son adquiridas durante el aprendizaje teórico o conceptual (Rodrigo, Rodríguez \& Marrero, 1993, p. 33). Sin embargo, en las expresiones de los estudiantes con respecto a la solución de situaciones de discriminación, y en sus acciones, rechazan o discriminan a algunos de los compañeros. Estos últimos comportamientos se asocian con aprendizajes derivados de estereotipos y prejuicios sociales, adquiridos de manera implícita en la cotidianidad (Pozo et al., 2006, p. 79).

En los resultados se encuentran diferencias con lo reportado en estudios previos sobre concepciones de diversidad en docentes, porque estos categorizan el mundo social con criterios jerárquicos (ejemplo, ciudadanos nacionales y extranjeros), que tienen un carácter nomotético (Sagastizabal et al., 2009, p. 126), mientras que los niños categorizan la diversidad desde situaciones específicas vinculadas con la vida cotidiana, con estereotipos y prejuicios, como los enunciados en los ejemplos anteriores.

Según la Psicología Social, en los estereotipos y los prejuicios las personas construyen categorías del mundo social a partir de la pertenencia o no, al propio grupo, comparándolo con otros grupos (exogrupo). Dicha categorización simplifica, naturaliza la complejidad del mundo y crea memoria selectiva en la formación de identidad social, con la que se explican o se justifican acciones contra grupos considerados externos, creando ideologías que legitiman la discriminación social (Jiménez \& Goenechea, 2014, p. 129).

Teniendo en cuenta que tanto las concepciones como los estereotipos y los prejuicios sociales simplifican y naturalizan el mundo social, por considerarlo un producto y no una construcción cultural dinámica, es necesario repensar las prácticas de enseñanza de la Educación para la Ciudadanía basadas en enfoques de ciudadanía nacional, que homogenizan y acentúan la desigualdad con quienes no hacen parte o no se identifican con el grupo cultural predominante. 


\section{CONCLUSIONES}

En los niños y las niñas de básica primaria participantes en el estudio se identifica que, por un lado, reconocen de manera verbal semejanzas y diferencias biológicas y culturales entre los miembros de los grupos a los que pertenecen y, a su vez, por otro lado, rechazan o discriminan a algunos de los compañeros de clase por su condición física, la procedencia, los gustos o las costumbres culturales.

Los estudiantes reconocen la diversidad desde situaciones específicas de su vida cotidiana, la relacionan con estereotipos y prejuicios que naturalizan el conocimiento social, lo homogenizan a la cultura dominante, actitud que limita la aceptación y el respeto de las diferencias al interior de cada grupo y entre grupos sociales.

Las prácticas de Educación para la Ciudadanía en las que se observan e identifican las concepciones de diversidad de los estudiantes, si bien fueron guiadas por casos y problemas relacionados con discriminación e injusticias cercanas a la vida de los estudiantes, responden a finalidades de la Educación para una ciudadanía nacional, que restringe el concepto de diversidad, factor que puede haber incidido en los resultados del estudio. En el otro lado se encuentra la formación para una ciudadanía global o planetaria, donde la diversidad es un valor y una oportunidad para la formación de una ciudadanía incluyente y de democracia social.

La identificación de las concepciones de diversidad de los estudiantes debe ser la base para una Educación Ciudadana basada en el diálogo, el debate, la argumentación y la contraargumentación, donde los estudiantes tengan la opción de hacer conscientes sus teorías implícitas y puedan iniciar procesos de transformación de los prejuicios y estereotipos sociales, que restringen la aceptación y el respeto por la diversidad.

Asimismo, en las prácticas de enseñanza para la formación de una ciudadanía crítica, también es esencial identificar las concepciones de ciudadanía y de diversidad de los profesores, puesto que, de sus concepciones sobre el tema, depende la superación de prácticas educativas centradas en la adquisición de contenidos teóricos alejados de la realidad de los contextos. También, es relevante una formación de pensamiento crítico en los estudiantes desde los primeros años de escolaridad, que les permita comprender la complejidad del mundo social en que viven y comprometerse con la construcción de democracia y justicia social.

\section{REFERENCIAS}

Barton, K. (Ed.) (2006). Research Methods in Social Studies Education. Contemporary Issues and Perspectives. Greenwich: Information Age Publishing.

Baubock, R. (2005). Transnational Citizenship. Membership and Rights in International Migration. Edward Elgar Publishing.

Cortina, A. (2009). Ciudadanos del mundo: Hacia una teoría de la ciudadanía. Madrid: Alianza Editorial.

Dietz, G., \& Mateos, L. (2013). Interculturalidad y educación intercultural en México: un 
análisis de los discursos nacionales e internacionales y su impacto en los modelos educativos mexicanos. Secretaría de Educación Pública (SEP) - Coordinación General de Educación Intercultural y Bilingüe (CGEIB).

Evans, R. W., \& Saxe, D. W. (1996). Manual de enseñanza de cuestiones sociales. Revista Internacional de Sociología de la Educación, 6(2), 268-270.

Felitti, K., \& Rizzotti, A. (Eds.) (2018). Enseñar y aprender en contextos interculturales. Saberes, herramientas y experiencias de educación internacional. Buenos Aires: Miño y Dávila Editores.

Flick, U. (2012). Introducción a la investigación cualitativa. (3a ed). Madrid: Ediciones Morata.

Flick, U. (2014). An Introduction to Qualitative Research. (5 a ed). Illinois: Sage Publications Ltd.

Flórez, E., \& Posada, L. (2020). Concepciones de diversidad en estudiantes de grado segundo de básica primaria (Trabajo de grado de maestría). Universidad Tecnológica de Pereira. Repositorio Institucional Universidad Tecnológica de Pereira.

Gutiérrez, M., Arana, D., \& Buitrago, O. (2016). El reconocimiento de la diversidad a partir de problemas socialmente relevantes en la educación primaria. En C. García, A. Arroyo \& A. Mediero (Eds.), Deconstruir la alteridad desde la Didáctica de las Ciencias Sociales: Educar para una ciudadanía global (pp. 194-201). Las Palmas de Gran Canaria: Entinema.

Hernández, R., Fernández, C., \& Baptista, P. (2014). Metodología de la investigación. México: McGraw-Hill Interamericana. Recuperado de: http://trabajodegradobarinas.blogspot. com/2013/07/metodologia-de-la-investigacion-2010-de.html

Huber, M. (2004). La situación problema como facilitador de la actividad del profesor de historia. Enseñanza de las ciencias sociales: revista de investigación, 3, 29-38. Recuperado de: https://www.raco.cat/index.php/EnsenanzaCS/article/view/126179

Jiménez, R., \& Goenechea, C. (2014). Educación para una Ciudadanía Intercultural. Madrid: Editorial Síntesis.

Kymlicka, W. (2003). La política vernácula. Nacionalismo, multiculturalismo y ciudadanía. Barcelona: Ediciones Paidós.

Legardez, A. (2004). Transposition didactique et rapports aux saviors l'exemple des enseignements de questions économiques et sociales, socialement vives. Revue française de pédagogie, 149, 19-27.

Lopéz, R. (2011). Conflictos sociales candentes en el aula. En J, Pagés \& A. Santisteban. Les qüestions socialment vives i l'ensenyament de les ciències socials. Universitat Autònoma de Barcelona.

Molina, A., \& Utges, G. (2011). Diversidad cultural, concepciones de los profesores y los ámbitos de sus prácticas. Dos estudios de caso. Revista de Enseñanza de la Física, 24(2), 7-26.

Molina, A., Mosquera, C., Utges, G., Mojíca, L., Cifuentes, M., Reyes, J., Martinez, C., \& Pedreros, I. (2014). Concepciones de los profesores sobre el fenómeno de la diversidad cultural y sus implicaciones en la enseñanza de las ciencias. Universidad Distrital Francisco José de Caldas.

Morin, E., Ciurana, E., \& Motta, R. (2002). Educar en la era planetaria: el pensamiento 
complejo como método de aprendizaje en el error y la incertidumbre humana. Universidad de Valladolid.

Pagès, J. (2007). ¿Qué se debería enseñar de historia hoy en la escuela obligatoria?, ¿qué deberían aprender, y cómo, los niños y las niñas y los y las jóvenes del pasado? Revista Escuela de Historia, 1(6), 17-30.

Pozo, J., Scheuer, N., \& Pérez, M. (2006). Nuevas formas de pensar la enseñanza y el aprendizaje: las concepciones de profesores y alumnos. España: Editorial Graó.

Rodrigo, M. J., Rodríguez, A., \& Marrero, J. (1993). Las teorías implícitas: una aproximación al conocimiento cotidiano Madrid: Aprendizaje/Visor.

Ruiz, A. (2018). Educación, literacidades y ciudadanía. Líneas actuales de debate. Cádiz: UNO editorial.

Sagastizabal, M., San Martín, P., Perlo, C., \& Pivvetta, B. (2009). Diversidad cultural y fracaso escolar: educación intercultural: de la teoría a la práctica. Argentina: Noveduc Editorial.

Santisteban, A. (2019). La enseñanza de las Ciencias Sociales a partir de problemas sociales o temas controvertidos: estado de la cuestión y resultados de una investigación. El Futuro del Pasado, (10), 57-79. http://doi.org/10.14516/fdp.2019.010.001.002

Schulz, W., Ainley, J., Cox, C., \& Friedman, T. (2018). Percepciones de los jóvenes acerca del gobierno, la convivencia pacífica y la diversidad en cinco países de América Latina: Estudio Internacional sobre Educación Cívica y Ciudadana 2016 de la IEA. Informe Latinoamericano. International Association for the Evaluation of Educational Achievement (IEA). Recuperado de: http://repositorio.minedu.gob.pe/handle/MINEDU/5773

Secretaría de Educación Municipal de Pereira. (2019). Listado de Instituciones Educativas. Recuperado de: http://www.pereiraeduca.gov.co/index.php/2013-01-29-22-58-20/listadode-instituciones-educativas.

Soysal, Y., Baubock, R., \& Bosniak, L. (2010). Ciudadanía sin nación. Bogotá: Siglo del Hombre Editores.

Strauss, A., \& Corbin, J. (2002). Bases de la investigación cualitativa: técnicas y procedimientos para desarrollar la teoría fundamentada. Medellín: Editorial Universidad de Antioquia.

UNESCO. (2015). Educación para la ciudadanía mundial: temas y objetivos de aprendizaje. UNESCO.

Urrutia, L. (2020). Concepciones de diversidad en estudiantes de grado segundo de educación básica primaria (Trabajo de grado de maestría). Universidad Tecnológica de Pereira. Repositorio Institucional Universidad Tecnológica de Pereira.

Yin, R. (2009). Case Study Research. Design and Methods. Illinois: Sage Publications Ltd. 